\title{
Community Fragmentation? A 15-Year Study of Residents Perception on Tourism Development
}

\author{
Xinqi Wu, Hong Hui \\ School of Business Administration, Chongqing University of Technology, Chongqing, China \\ Email: hhzrj@cqut.edu.cn
}

How to cite this paper: $\mathrm{Wu}, \mathrm{X} . \mathrm{Q}$. and Hui, H. (2018) Community Fragmentation? A 15-Year Study of Residents Perception on Tourism Development. Journal of Service Science and Management, 11, 609-617. https://doi.org/10.4236/jssm.2018.116041

Received: June 17, 2017

Accepted: December 7, 2018

Published: December 10, 2018

Copyright ( $) 2018$ by authors and Scientific Research Publishing Inc. This work is licensed under the Creative Commons Attribution International License (CC BY 4.0).

http://creativecommons.org/licenses/by/4.0/

(c) (i) Open Access

\begin{abstract}
Tourism development may result in polarization among the community residents with simple social relations, mutual misunderstanding or even hostility between the foreign residents and indigenous residents. Such conflict and estrangement between resident relationship is called the "effect of community fragmentation" of tourism development. Based on a study of Ciqikou, which is an ancient town, this paper found that, the "effect of community fragmentation" did exist and such effect may cause the "crowding-out effect", which would influence the continuous development of tourism. Therefore, the paper proposes that a new benefit mechanism for tourism must be explored, to benefit all the residents in scenic region from the tourism development; to avoid the "crowding-out effect", legislation based on house reservation to indigenous residents must be enacted to ensure their residences would not be occupied by external capital; tourism development must take the realization of community development as the basic target.
\end{abstract}

\section{Keywords}

Community, Residents Perception, Tourism Development

\section{Introduction}

The living of community residents will be inevitably affected by the tourism development when this community became a tourist destination [1]. Therefore, the study of tourism impact has been a hot topic of domestic and foreign scholars [2] [3], including the economic impact of tourism, social and cultural impact, environmental impact, residents' perception on tourism impact [4]. The residents may feel different tourism impacts due to age, gender, cultural background and other differences [5]. For example, Wilkinson's study of the island of Java found that foreign residents had more economic benefits than indigenous resi- 
dents because they had capital or mastered relevant professional skills [6]. Walpole's findings on the Komodo National Park in Indonesia also yielded similar conclusions [7]. Residents living in the same community are likely to have a negative impact on the relationship if the difference in economic benefits from tourism is too large. For instances, it may result in hostility between the foreign residents and indigenous residents, or gaps among residents with different cultural backgrounds, which would cause polarization among the community residents with simple social relations, or some residents are marginalized and so on.

Such conflict and estrangement between resident relationship is called the "effect of community fragmentation" of tourism development.

In order to study the effect that tourism brings on the community, this paper chooses the ancient town "Ciqikou" in Chongqing as the object of study, and analyzes the influence of tourism development on the relationship between foreign residents and indigenous residents, and the phenomenon of community polarization.

This paper chooses the ancient town "Ciqikou" in Chongqing as the object of study. The town was built in the Ming Dynasty, with a long history of thousands of years, only $3 \mathrm{~km}$ away from the city center of Shapingba District. The territory of the town is $1.5 \mathrm{~km}^{2}$, and its population has increased from 15,000 in 2003 to 18,000 in 2008. The town began its tourism development since 1999, and developed part of its main street and cross street in 2003, at that time, the number of tourists received was about 50,000 per year, and now is about 300 million people per year, which was 60 times than in 2003, while the proportion of the local population rose from 1:3.3 to 1:167. (Table 1) The author analyzes the residents' perception of tourism through the fifteen-year follow-up observation of Ciqikou Town, and finds that the effect of social diving exists.

\section{Research Method}

Based on the survey data of 2003, 2008 and 2017, this paper studies the perception and dynamic change of the residents on tourism impact in Ciqikou, to analyze the influence of the tourism development on the local residents and to determine whether the community has emerged the phenomenon of community fragmentation.

\subsection{Questionnaire Design}

The questionnaire consists of three parts. The first part is some of the questions about demographic statistics, including gender, age, income, job, housing nature,

Table 1. Residents and tourists change.

\begin{tabular}{cccc}
\hline Year & Residents (thousand) & Tourists (thousand) & Ratio(R/T) \\
\hline 2003 & 15 & 50 & $1 / 3.3$ \\
2008 & 18 & 3000 & $1 / 167$ \\
2017 & 3 & 10,000 & $1 / 3333$ \\
\hline
\end{tabular}


residence location, period of residence, etc.; The second part is to measure the overall perception of community residents on tourism, including the scale of tourism, tourism benefit and other issues; The third part is to understand the perception of residents on social impact, economic impact and environmental impact of tourism. Among which, the second and third parts require residents to demonstrate their acceptance of the views listed in the questionnaire by the $1-5$ (Likert scale) rank method. (1) Strongly disagree; 2) Disagree; 3) Basically agree; 4) Agree; 5) Strongly agree).

\subsection{Sample Analysis}

As shown in Table 2, the number of valid questionnaires collected in 2003 and 2008 was 167 out of 170 families and 133 out of 180 families, respectively. In the 2017 survey, 85 families completed 74 valid questionnaires. The change in the basic demographic characteristics of the survey sample reflects a corresponding change in the social characteristics of the area. For example, in the 2003 survey, young adults aged 20 - 39 accounted for only $9 \%$ of the total population surveyed (which coincided with the age constitution characteristics of a few at each extreme and many in between), and it rose to $28 \%$ in the 2008 , which reflects a large number of young labors moving in. The proportion of foreign residents increased from $11 \%$ in 2003 to $67 \%$ in 2017, and has become a major component of the community population structure. The population of the developed block has risen from $19 \%$ to $30 \%$, which indicates a limited expansion of the development area of the town. The proportion of indigenous residents fell from $89 \%$ to $50 \%$, which means not only a part of new residents moving in, but also part of indigenous residents who cannot adapt the tourism development then moving out.

Table 2. Comparison of sample characteristics in 2003, 2008, 2017.

\begin{tabular}{|c|c|c|c|c|}
\hline Category & Subclass & 2003 & 2008 & 2017 \\
\hline \multirow{3}{*}{ Age } & $20-39$ & $9 \%$ & $28 \%$ & $13 \%$ \\
\hline & $40-59$ & $59 \%$ & $28 \%$ & $60 \%$ \\
\hline & Above 60 & $32 \%$ & $44 \%$ & $27 \%$ \\
\hline \multirow{2}{*}{ Accommodation } & Foreign resident & $11 \%$ & $50 \%$ & $67 \%$ \\
\hline & Indigenous resident & $89 \%$ & $50 \%$ & $33 \%$ \\
\hline \multirow{2}{*}{ Gender } & Male & $49 \%$ & $40 \%$ & $65 \%$ \\
\hline & Female & $51 \%$ & $60 \%$ & $35 \%$ \\
\hline \multirow{3}{*}{ Residential location } & Developed block & $19 \%$ & $30 \%$ & $3 \%$ \\
\hline & Undeveloped block & $81 \%$ & $65 \%$ & $0 \%$ \\
\hline & Nearby resident & $0 \%$ & $5 \%$ & $97 \%$ \\
\hline \multirow{2}{*}{ Profession } & Unemployed & $39 \%$ & $16 \%$ & $27 \%$ \\
\hline & Employed & $61 \%$ & $84 \%$ & $73 \%$ \\
\hline
\end{tabular}




\subsection{Survey Result}

The results of the $\mathrm{T}$ analysis on the perceptual dimension show (Table 3) that significant differences in interpersonal relationships, polarization, macroeconomic development, environmental pollution and the good than harm exist between 2003 and 2008 years.

\subsubsection{Change of Residents' Perception on Polarization}

Found in the 2003 survey, local residents basically didn't agree with the existence of polarization, while in 2008, 24\% fully agreed and 34\% agreed with the polarization increasing, the average points decreased from 4.7 to 2.33, and in 2017 to 2.20 , which means that residents fully agree that polarization is intensifying. (Table 4) During the recent survey, we can find the points continue to decline, which means the polarization is obvious.

\subsubsection{Differences between the Perception of Foreign and Indigenous Residents on Tourism Impact}

In Table 5, as there were rare foreign residents in 2003 which may cause large the randomness of the data, so this paper did not use the survey data of 2003 in this study. We found that foreign residents hope that the scale of tourism development continues to expand in the survey of 2008 , and they are satisfied with

Table 3. T analysis of perception dimension.

\begin{tabular}{ccc}
\hline & Variance & p value \\
\hline Interpersonal relationships & Unequal & 0.030 \\
Social atmosphere & Equal & 0.000 \\
Social security & Equal & 0.000 \\
Living standard & Equal & 0.001 \\
Traffic & Equal & 0.228 \\
Income level & Equal & 0.000 \\
Employment & Equal & 0.000 \\
Commodity prices & Equal & 0.510 \\
Polarization & Unequal & 0.000 \\
Macroeconomic development & Unequal & 0.002 \\
traditional culture & Equal & 0.000 \\
Environmental pollution & Unequal & 0.002 \\
good than harm & Unequal & 0.738 \\
\hline
\end{tabular}

Table 4. Perception change on polarization.

\begin{tabular}{cc}
\hline Year & Feeling the polarization is becoming serious \\
\hline 2003 & 4.70 \\
2008 & 2.33 \\
2017 & 2.20
\end{tabular}


Table 5. Differences between the perception of foreign and indigenous residents on tourism impact (data of 2008 and 2017).

\begin{tabular}{|c|c|c|c|}
\hline Type of resident & Year & $\begin{array}{l}\text { Foreign } \\
\text { resident }\end{array}$ & $\begin{array}{c}\text { Indigenous } \\
\text { resident }\end{array}$ \\
\hline \multirow{2}{*}{ Love tourists } & 2008 & 1.74 & 2.58 \\
\hline & 2017 & 2.85 & 3.35 \\
\hline \multirow{2}{*}{ Hope more tourists } & 2008 & 1.76 & 2.43 \\
\hline & 2017 & 2.81 & 3.25 \\
\hline \multirow{2}{*}{ Tourism development does more good than harm } & 2008 & 2.00 & 2.30 \\
\hline & 2017 & 2.32 & 2.26 \\
\hline \multirow{2}{*}{ The tourism industry is developing well } & 2008 & 2.26 & 2.85 \\
\hline & 2017 & 2.07 & 2.32 \\
\hline \multirow[b]{2}{*}{ Income increases } & 2008 & 2.42 & 2.21 \\
\hline & 2017 & 1.49 & 1.98 \\
\hline \multirow{2}{*}{ Local employment increases } & 2008 & 2.74 & 3.55 \\
\hline & 2017 & 2.69 & 2.78 \\
\hline \multirow{2}{*}{ Mainly make a fortune to foreign residents } & 2008 & 2.50 & 1.58 \\
\hline & 2017 & 2.09 & 2.38 \\
\hline \multirow{2}{*}{ Interpersonal relationships decline } & 2008 & 3.55 & 3.16 \\
\hline & 2017 & 3.19 & 2.75 \\
\hline \multirow{2}{*}{ Social atmosphere decline } & 2008 & 3.15 & 2.70 \\
\hline & 2017 & 2.99 & 2.57 \\
\hline \multirow[b]{2}{*}{ Social security declined } & 2008 & 2.91 & 2.69 \\
\hline & 2017 & 3.28 & 3.07 \\
\hline \multirow{2}{*}{ Loss of traditional culture } & 2008 & 2.94 & 2.48 \\
\hline & 2017 & 3.0 & 2.67 \\
\hline \multirow[b]{2}{*}{ Cannot find a place to drink tea } & 2008 & 3.62 & 2.96 \\
\hline & 2017 & 3.29 & 3.18 \\
\hline \multirow{2}{*}{ Cannot find a place where children play } & 2008 & 3.18 & 2.58 \\
\hline & 2017 & 2.38 & 3.14 \\
\hline \multirow{2}{*}{ Too noisy } & 2008 & 3.09 & 2.54 \\
\hline & 2017 & 1.84 & 2.37 \\
\hline \multirow{2}{*}{ Environmental pollution } & 2008 & 2.62 & 1.94 \\
\hline & 2017 & 2.85 & 2.72 \\
\hline
\end{tabular}

the development status of Ciqikou. This is because the foreign residents generally do a small business in Ciqikou, or they are migrant workers, therefore, the feelings to this town are few and the possession to the community is the lowest, the development of Ciqikou for them is mainly reflected on the economic interests. They believe that the further development of Ciqikou will bring them more 
economic benefits, so the degree of how much they like the tourists and the degree of support are higher. Residents living in the community here for a long time are the most dependent on the community, they are eager to further sustainable development of the community, so they hold a more cautious attitude to the continued growth of tourists.

In terms of promoting local employment, the average value of perception of indigenous residents is above 3 , and they do not agree with that the employment increased, which indicates that the promotion from tourism development has little effect on local employment. Therefore, from this point of view, the indigenous residents believe that the main beneficiary is foreign resident. There is a very interesting phenomenon, the perception of income increase from foreign residents is much lower than of local residents. While the local residents strongly believe that the tourism mainly makes a fortune to foreign residents. This has in fact created a gap between indigenous and foreign residents. They believe that the other party gains more benefits from tourism development.

Residents living here for generations have stronger sense of social attitudes, social order, decline in interpersonal relationships and loss of traditional culture than foreign residents, for they are more aware of social change, at the same time, they are more aware of the "the loss of traditional culture", because this is the heritage of their precious cultural wealth.

Indigenous residents think that living space is indeed occupied, while foreign residents think that living space has not been deprived. This is because the indigenous residents have a high dependence on Ciqikou, their ancestors lived a comfortable and leisurely life here, and they have deeper perception of excessive tourist population would occupy their living space after the tourism development.

On the issue of environmental pollution, residents who have a high dependence on the community have stronger perception of environmental pollution. This is because the indigenous residents have greater expectations on the environmental quality, and cherish their long-term living environment more.

From a long term study, we can find that the community fragmentation continue to expand.

\subsubsection{Differences among Overall Perception of Different Age Groups on Tourism Impact}

As shown in Table 6, the older the population is less supportive of tourism

Table 6. Differences among perception of different age groups on tourism impact.

\begin{tabular}{cccc}
\hline Age & $\begin{array}{c}\text { Tourism development } \\
\text { does more good than harm }\end{array}$ & $\begin{array}{c}\text { The tourism industry } \\
\text { is developing well }\end{array}$ & Love the tourist \\
\hline $20-39$ & 2.38 & 2.59 & 2.35 \\
$40-59$ & 2.32 & 2.70 & 2.46 \\
Above 60 & 4.08 & 4.41 & 2.18 \\
Total average & 3.16 & 3.48 & 2.30 \\
\hline
\end{tabular}


development. The overall perception of residents aged over 60 in Ciqikou is very negative on tourism development. Most elderly people do not think that living standards improve, and they disagree with the opinion of "Tourism development does more good than harm", also are strongly dissatisfied with the status quo of tourism development. The reason is that the elderly benefit less in the tourism development. They seem to prefer the previous state of life, and they have a deep memory of the past life of Ciqikou, but they do not dislike tourists, this can show that the elderly enjoy the hustle and bustle of life, they like tourists, but dissatisfy with the current development model. The foundation of tourism development lies in the long history and culture, and the elderly should be an important carrier of the culture of ancient town, the way of their life and cultural heritage are important wealth of tourism development in Ciqikou. Unfortunately, they are opposed to the development of tourism, which shows there are significant differences in the benefited population of tourism development in Ciqikou, of which the elderly benefits less.

\section{Conclusions}

Tourism development is likely to cause the division of indigenous and foreign residents. For example, the interest point and community dependence level are different between indigenous and foreign residents in Ciqikou, especially since most local residents believe that the economic benefits of tourism development are mainly occupied by foreign residents. This perception is likely to cause the separation among residents as well as social injustice, also easily leads to misunderstanding and conflict among different groups of people in the community. The development of this state will affect the community's construction, which may cause "double lose" situation: Foreign residents are difficult to integrate into the community, they only regard the scenic area as a temporary place to make money, they do not want to put the income into the community construction, and ultimately it will affect the indigenous residents, thus affect the sustainable development of the tourism industry.

Due to the different benefits of the various groups in the tourism development, and the differences of perception in the process of social change, it is easy to lead to the separation between the local residents. The model of tourism development in Ciqikou is difficult to benefit all the residents. As a member of the community, all the residents are part of the town, therefore they all should benefit from the tourism development of this town. The uneven benefits of the residents are essentially a certain of social injustice, which indicates that the current tourism development in the town focuses too much on efficiency while less on social equity.

Tourism development will lead to the "crowding-out effect". The "crowding-out effect" refers to the phenomenon that due to the development of tourism, the original residents were excluded from scenic spots, especially during the tourism process which takes traditional culture as the object, such as ancient 
town tour. Most of the residents in the scenic area have low incomes and low educational level. At the early stage of tourism development, they have a high enthusiasm for tourism development. However, with the further development of tourism, foreign capital and foreign labor force into the town gradually, indigenous residents are unable to compete with foreign populations due to weak economic strength and job skills; therefore, they are gradually marginalized and excluded from the beneficiaries. Besides, with the further deterioration of the environment and increase in social costs, part of the local residents is spontaneously or forced to move out from the original residence. Of course, some indigenous residents are squeezed out due to government or developers. During the last investigation in 2017, we found that due to the expansion of the scenic spot, which would lead to better economic development of this territory, the government pulled down most houses and moved the original residents to some other places. This phenomenon is worrying; in fact, the indigenous resident is the living heritage and soul of the ancient town. The town will be a shell without indigenous residents. So with the development of this place, the original residents can not share the development, and the community is disappearing Crowding-out effect will eventually lead to the decline of the native culture. Ancient town is the cultural heritage which is unable to reproduce or copy, it is the precious culture left by our ancestors. We have no reason to destroy them for some short-term economic benefits.

\section{Propose}

First, a new benefit mechanism for tourism must be explored, to benefit all the residents in scenic region from the tourism development. Residents in scenic area have bear corresponding cost for tourism development, they all should be the beneficiaries regardless of the education level, age or house location. At present, the tourism development of Ciqikou or even of the majority of scenic spots in China has ignored the principle of fair distribution, which promotes the emergence of polarization, resulting in community population separation, and ultimately it will affect the construction of scenic areas and harmonious development of the community. Therefore, we must rely on the local residents spontaneously or with the help of external forces to form a fair and equitable benefit mechanism, so that all residents can become the beneficiaries of scenic spot development.

Second, to avoid the "crowding-out effect", legislation based on house reservation to indigenous residents must be enacted to ensure their residences would not be occupied by external capital. many foreign investors will consider occupying local residential house or land due to the local land price appreciation caused by tourism development. Even if the local residents do not want to relocate, they are unable to fight against the government or developers. Therefore, in order to protect the original ecology of cultural attractions, it must enact legislation protection on this kind of residential housing, to forbid the overall relocation of the residents. 
Third, tourism development must take the realization of community development as the basic target. Under the premise of protecting the interests of the residents in the scenic spot, coordinate the interests of countries, regions and other tourism participants. Tourism development must serve the community residents, the fundamental purpose of tourism development is nether to increase government revenue, nor to please the tourists, but to improve the quality of life of community residents, and promote the development of community. Tourism development without community development is unsustainable and predatory (especially the ancient town tour). Only a healthy and happy town can attract tourists and achieve a win-win development of tourism and community.

\section{Limitations}

The research object of this paper only involves a single scenic spot, and whether the research conclusion is universal to other scenic spots that also carry out tourism planning is unknown. In future studies, the universality of the research results can be increased by studying scenic spots of multiple types and regions.

\section{Conflicts of Interest}

The authors declare no conflicts of interest regarding the publication of this paper.

\section{References}

[1] Murphy, P.E. (1985) Tourism: A Community Approach. Methuen, New York and London, 1.

[2] Zhang, L.S. (2004) On the Progress of Foreign Tourism Research in Recent Years-An Analysis of Papers Published in the Annals of Tourism Research. Tourism Tribune, 19, 82-88.

[3] Zeng, J. (2006) A Study Summary of the Tourism Impact of Overseas in Recent Years Based on the Literatures of Annals of Tourism Research. Yunnan Geographic Environment Research, 18, 79-82.

[4] Zhang, X.M. and Bao, J.G. (2004) The Assessment of Tourism Impact on Regional Economy: A Review. Journal of Guilin Institute of Tourism, 15, 2.

[5] Liu, D.X. and Qin, Y.H. (2008) Residents' Perceptions and Attitudes toward the Impact of Tourism: A Case Study of Golden Buddha Mountain in Nanchuan of Chongqing, China. Journal of Southwest University (Socal Sciences Edition), 34, 133-136.

[6] Wilkinson, P.F. and Pratiwi, W. (1995) Gender and Tourism in an Indonesion Village. Annals of Tourism Research, 22, 283-299. https://doi.org/10.1016/0160-7383(94)00077-8

[7] Walpole, M.J. and Goodwin, H.J. (2000) Local Economic Impacts of Dragon Tourism in Indonesia. Annals of Tourism Research, 27, 559-576. https://doi.org/10.1016/S0160-7383(99)00088-2 